\title{
Prevalence of Thyroid Hormone Dysfunction among Female Patients, Attending A Multispeciality Hospital In Manipur
}

\author{
${ }^{1}$ Dr. Arpita Das, ${ }^{1}$ Dr. Shaini L, ${ }^{1}$ Dr. Sangeeta N, ${ }^{2}$ Dr. Saurav Paul, ${ }^{1}$ Dr. \\ Chanchal L, ${ }^{3}$ Dr. Sachin Deba Singh, ${ }^{4}$ Dr. Ahilya P. \\ ${ }^{I}$ Department of Biochemistry, RIMS \\ ${ }^{2}$ Department of Social and Preventive Medicine, RIMS \\ ${ }^{3}$ Department of Medicine, RIMS \\ ${ }^{4}$ Ex-CMO, Casualty Department, RIMS
}

\begin{abstract}
Introduction: Thyroid disease is a chronic non-communicable disease affecting women more than male. About 20 million Americans have some form of thyroid dysfunction, mostly women and about forty million individuals suffering in India. Objective of this study is the prevalence of thyroid hormone dysfunction in female patients as hypo or hyperthyroidism in the Dept of biochemistry, RIMS, Imphal.

Materials and methods: This cross-sectional study was conducted in the Deptt. of Biochemistry, RIMS, Imphal in collaboration with Deptt. of Medicine on 824 female patients from January 2010 to December 2012.Thyroid function test were assayed by the ELISA method.

Results and observations: In this study, out of 824 female patients enrolled, 491 patients are below 40 yrs and 333 patients are above 40 yrs. The present study shows that prevalence of hypothyroidism and hyperthyroidism in females are $19.1 \%$ and $13.7 \%$ respectively and also shows that prevalence of hypothyroidism is more common in females of hilly areas (23.8\%) compared to valley or plain areas $(16.2 \%)$.

Conclusion: Hypothyroidism is the most common thyroid dysfunction in the female population of Manipur so screening is needed above 40 yrs of female and for people of hilly areas of Manipur.
\end{abstract}

KeyWords; female patients, hypothyroidism, hilly areas, $T_{3,} T 4, T S H$.

\section{Introduction}

Thyroid disease is being increasingly diagnosed with greater awareness and is one of the chronic noncommunicable disease affecting women more, though male population is not spared of the ailment. Thyroid is a butterfly-shaped gland in the neck region, just above collarbone. It is one of the endocrine glands, which make hormones. The thyroid hormones, thyroxine (T4) and triiodothyronine (T3) are tyrosine-based hormones produced by the thyroid gland primarily to regulate metabolism. An important component in the synthesis of thyroid hormones is iodine. The major form of thyroid hormone in the blood is thyroxin (T4). The thyroid also produces the hormone calcitonin, which plays a role in calcium homeostasis. Thyroxine increases cardiac output, heart rate, basal metabolic rate, ventilation rate, potentiates brain development, and potentiates the effects of catecholamines (i.e. increases sympathetic activity), and thickens the endometrium in females. These hormones also regulate protein, fat, and carbohydrate metabolism, to see human cells using their energetic compounds. They also stimulate vitamin metabolism. Numerous physiological and pathological stimuli influence thyroid hormone synthesis. Both excess (hyperthyroidism) and deficiency (hypothyroidism) of thyroxine can cause disorders. Hyperthyroidism is the clinical syndrome caused by an excess of circulating free thyroxin, free triiodothyronine, or both. The symptoms of hyperthyroidism are fast heart rate, nervousness, increased perspiration, muscle weakness, trembling hands, weight loss, hair loss, skin changes, increased frequency of bowel movements, decreased menstrual flow and less frequent menstrual flow, goiter and exopthalmus. $[1,12]$ Hypothyroidism is the case where there is a deficiency of thyroxin, triiodiothyronine, or both. The symptoms of hypothyroidism are feeling slow or tired, cold, drowsy, slow heart rate, poor memory, difficulty in concentrating, muscle cramps, weight gain, husky voice, thinning hair, dry and coarse skin, feeling depressed, heavy menstrual flow, milky discharge from the breasts and infertility [1].

About 20 million Americans have some form of thyroid disease and most of them are women. It is estimated that there are at least forty million individuals with thyroid disease in India. Most of them are women, and most hypothyroidism occurs after the birth of a baby, called postpartum hypothyroidism [1]. The American Thyroid Association recommends that adults must be screened for thyroid dysfunction by measurement of the serum thyrotropin concentration at the age 35 years and every 5 years thereafter. $[1,13]$

Thyroid diseases are most common among women and if not treated in time it can lead to severe health problems. Hypothyroidism is more common in older women and 10 times more common in women than men [2]. The prevalence of hyperthyroidism is also reported as more common in women than men. Objective of this 
work is to study the prevalence of thyroid hormone dysfunction in female patients in the form of hypo or hyperthyroidism in the Dept of biochemistry, RIMS, Imphal.

\section{Study design}

\section{Materials And Methods}

The study was conducted in the Department of Biochemistry, RIMS (Regional Institute Of Medical Sciences), Imphal in collaboration with Department of Medicine. The present study was started after obtaining ethical clearance from the institutional ethical committee. Informed consent was obtained from the individual patients.

It is a cross-sectional study conducted on all the female patients attending in the Dept of biochemistry, RIMS. Imphal for thyroid function test (T3, T4, TSH) from January 2010 to December 2012, around 824 patients were enrolled in the study group. Subjects with incomplete thyroid functions test and subclinical thyroid hormone levels (as clinical assessment of subjects was not done) and those not willing to sign the consent letter were excluded from the study group. The age, sex and location of the subjects were also noted. Most of the subjects of the study were resident of Imphal districts.

\section{Collection of blood samples}

After overnight fasting $3 \mathrm{ml}$ of venous blood samples were collected in morning in plain vials under aseptic conditions from the subjects attending RIMS, Biochemistry Dept. Blood was allowed to clot and centrifuged at $3000 \mathrm{rmp}$ for 15 minutes at room temperature. The separated serum was stored at $-20^{\circ} \mathrm{c}$ for hormone assay

\section{Assay of thyroid function panel}

Thyroid function test panel (T3, T4, TSH) were assayed by the ELISA method using ELISCAN kit with the help of MULTISKAN auto analyzer and all three parameters were estimated by following the same standard protocol provided by the manufacturer (RFCL, India).

\section{Criteria for thyroid dysfunction}

The reference interval for T3, T4 and TSH were $0.6-2.02 \mathrm{pg} / \mathrm{ml}, 4.4-11.6 \mathrm{ng} / \mathrm{dl}$ and $0.39-6.16 \mathrm{IU} / \mathrm{ml}$ respectively. Thyroid function is normal or euthyroid when T3, T4 and TSH values are in normal range. When increased TSH but decreased T3 and T4 level the condition is called hypothyroidism and when T3 and T4 are increased and TSH level decreases, the condition is called hyperthyroidism.

\section{Statistical analysis}

The data were entered and analyzed by the Software Package for Social Sciences, version 16 (SPSS16). The data were represented as percentage, frequency, mean. The Chi-square test was applied. The data were considered as significant at a $\mathrm{P}$ value of 0.05 .

\section{Results And Observations}

In present study, a total of 824 female patients were enrolled from January 2010 to December 2012. Out of 824 patients 491 patients are below 40 yrs and 333 patients are above 40 yrs. Mean age of the study group is $38.28 \pm 12.8$ yrs. The subjects were classified according to thyroid status as hypothyroidism, hyperthyroidism and euthyroidism. The present study shows prevalence of hypothyroidism in female is $19.1 \%$ and prevalence of hyperthyroidism in female is $13.7 \%$ and total euthyroid is $67 \%$. Present study shows over 40 years, prevalence of both hypothyroidism (19.2\%) or hyperthyroidism (14.2\%) increases but the values are not statistically significant $(\mathrm{p}$ value $=0.77, \mathrm{p}$ value $=0.08)$. The present study shows hypothyroidism is more prevalent (23.1\%) in muslim female patients than Hindu and Christian in Manipur which is statistically significant ( $\mathrm{p}$ value 0.006 ) and hyperthyroidism is also more prevalent in muslim female patients $(18.8 \%)$ than Hindu and Christian but the value is statistically insignificant $(\mathrm{P}=0.74)$. 


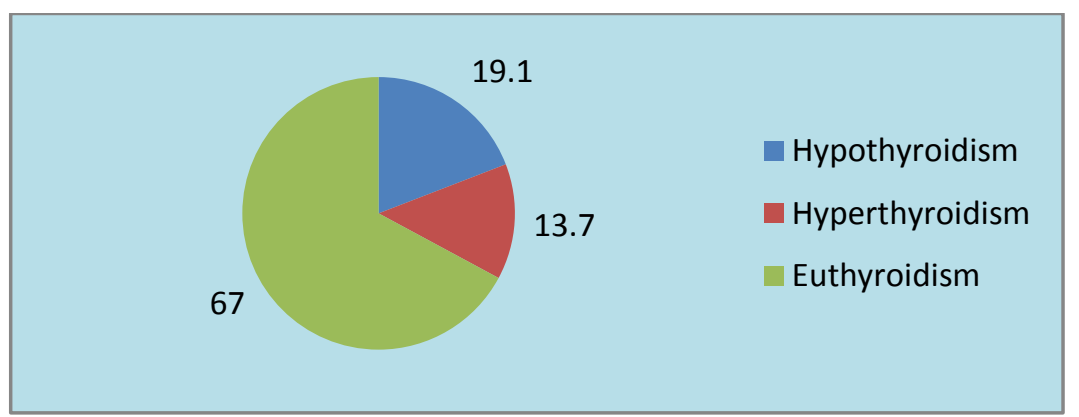

Fig 1: showing distribution of hypothyroidism, hyperthyroidism and euthyroidism

Table 1: Association between age and thyroid status

\begin{tabular}{|c|c|c|c|c|c|}
\hline Age & & SH value & & Total & $P$ value \\
\hline & $<0.39$ & $0.39-6.17$ (normal) & $>6.17$ & & \multirow{3}{*}{0.77} \\
\hline $0-40 \mathrm{yrs}$ & $35(7.13)$ & $363(73.9)$ & $93(18.8)$ & 491 & \\
\hline$>40 \mathrm{yrs}$ & $28(8.4)$ & $241(72.4)$ & $64(19.2)$ & 333 & \\
\hline \multicolumn{6}{|c|}{$\mathbf{T}_{3}$ and $\mathbf{T}_{4}$ values } \\
\hline & $<0.0 .69$ & $0.69-2.02$ (normal) & $>2.02$ & & \multirow{3}{*}{0.08} \\
\hline $0-40 \mathrm{yrs}$ & $80(16.2)$ & $345(70.2)$ & $66(13.6)$ & 491 & \\
\hline$>40$ yrs & $36(10.8)$ & $250(75.0)$ & $47(14.2)$ & 333 & \\
\hline
\end{tabular}

Table1 shows that more than 40 yrs patient have maximum numbers of hypothyroidism as well as hyperthyroidism cases compared to $<40 \mathrm{yrs}$ age group but this relation is not statistically significant $(\mathrm{p}=0.77$, 0.08 )

Table 2: Association between religion and thyroid status

\begin{tabular}{|c|c|c|c|c|c|}
\hline Religion & \multicolumn{3}{|c|}{ TSH value } & Total & P value \\
\hline & $<0.39$ & $0.39-6.17$ (normal) & $>6.17$ & & \multirow{4}{*}{0.006} \\
\hline Christian & $19(7.7)$ & 191(76.7) & $39(15.6)$ & 249 & \\
\hline Hindu & $32(6.4)$ & $372(73.5)$ & $102(20.1)$ & 506 & \\
\hline Muslim & $12(17.5)$ & $41(59.4)$ & $16(23.1)$ & 69 & \\
\hline \multicolumn{6}{|c|}{$T_{4}$ and $T_{3}$ values } \\
\hline & $<0.0 .69$ & $0.69-2.02$ (normal) & $>2.02$ & & \multirow{4}{*}{0.74} \\
\hline Christian & $34(13.8)$ & $180(72.2)$ & $35(14.0)$ & 249 & \\
\hline Hindu & $73(15.0)$ & $36872.2)$ & $65(12.8)$ & 506 & \\
\hline Muslim & $9(13.1)$ & $47(68.1)$ & $13(18.8)$ & 69 & \\
\hline
\end{tabular}

Above Table2 shows that Muslim patients have maximum numbers of hypothyroidism as well as hyperthyroidism cases compared to other religions but this relation is statistically significant only in case of hypothyroidism $(\mathrm{p}=0.006)$ but not in case of hyperthyroidism $(\mathrm{p}=0.74)$. The present study shows that the prevalence of hypothyroidism is more common in the female of hilly area $(23.8 \%)$ compared to valley or plain area $(16.2 \%)$ which is statistically significant $(\mathrm{p}=0.01)$. In case of hyperthyroidism similar finding like prevalence is more common in hilly area $(18.6 \%)$ which is also statistically significant $(\mathrm{p}=0.006)$.

Table 3: Association between area of living and thyroid status

\begin{tabular}{|c|c|c|c|c|c|}
\hline Area of living & \multicolumn{3}{|c|}{ TSH value } & \multirow[t]{2}{*}{ Total } & \multirow{4}{*}{$\begin{array}{l}\mathrm{P} \text { value } \\
0.01\end{array}$} \\
\hline & $<0.39$ & $0.39-6.17$ (normal) & $>6.17$ & & \\
\hline Valley area & $44(8.4)$ & $390(75.2)$ & $84(16.2)$ & 518 & \\
\hline Hilly area & $19(6.2)$ & $214(69.9)$ & $73(23.8)$ & 306 & \\
\hline \multicolumn{6}{|c|}{$\mathrm{T}_{3}$ and $\mathrm{T}_{4}$ values } \\
\hline & $<0.0 .69$ & $0.69-2.02$ (normal) & $>2.02$ & & \multirow{3}{*}{0.006} \\
\hline Valley area & $77(14.8)$ & $385(74.3)$ & $56(10.8)$ & 518 & \\
\hline Hilly area & $39(12.7)$ & $210(68.6)$ & $57(18.6)$ & 306 & \\
\hline
\end{tabular}

Table 3 shows that Hilly area has significantly higher proportion of both hypo and hyper thyroid cases compared to the valley area (Imphal, Thoubal, Moirang) 


\section{Discussion}

The estimates of the prevalence of thyroid dysfunction depend upon the methodological factors, the classifications of thyroid dysfunction, and the composition of the community, which are examined by age, ethnicity, and gender, making comparisons between the studies of limited value. The prevalence and the pattern of hypo or hyperthyroidism depend on ethnic, geographic, and environmental factors, which include the iodine intake status. [2, 9] TSH plays critical role in diagnosing TSH of thyroid disorders. [3, 10]

In the present study we have taken only female subjects for our study group because thyroid dysfunction is more common in women than men. The percentage of thyroid dysfunction among women was $13 \%$ among men was $5 \%$ [3]. In the present study, the prevalence of hypothyroidism $(19.1 \%)$ were higher than hyperthyroidism $(13.7 \%)$ and it was also seen that hypo or hyperthyroidism were more prevalent in hilly areas of Manipur. Hypothyroidisms are generally associated with iodine deficiency. Soil erosion with washing away of iodine from soil in hilly areas, use of non iodized salts and intake of various goitrogens may also have aggravated the problems.

Researchers from New Delhi had shown that the hypothyroidism was linked to iodine deficiency and this resulted in decompensated hypothyroidism in many cases [4]. In study conducted by Niafar M et al. hypothyroidism was common in Iranian population, as $12.8 \%$ of woman and $4.7 \%$ of man had hypothyroidism. However most of them were mildly hypothyroid [5]. As in others studies in developed countries, hypothyroidism tends to increase with age and is more common in women, and people with goiter $[6,8]$. In the present study, the prevalence of hypo or hyperthyroidism (19.2\% and $14.2 \%)$ is more common above 40 yrs of age. A study reported that hypothyroidism was more prevalent (40.5\%) in the age group of 36-45 yrs with obvious female preponderance.[6, 11] A study in Makkah exhibited similar age group predominance of $40 \pm 12$ years on the prevalence of thyroid disorders [7]. In childhood too, hypothyroidism can occur. In a clinic-based study from Mumbai, out of 800 children with thyroid disease, $79 \%$ had hypothyroidism. Common causes of hypothyroidism in these children were thyroid dysgenesis, dyshormonogenesis, and thyroiditis. $[7,14]$

There are few limitations of this study. The TSH test result is an excellent tool for screening of new patients for thyroid disease but the complete thyroid panel is needed for an accurate diagnosis and assessment of thyroid function. In the present study T3, T4, TSH was measured but free T3 and free T4 were not measured. Sub clinical hypo or hyperthyroidism is an important part of the thyroid disorder which can give accurate number of hypo or hyperthyroidism but we excluded it from the study, because clinical assessment of the patients were not done. The cut offs used were those recommended by the manufacturer of the kit.

\section{Conclusion}

This is the first study solely done on female subjects in case of thyroid dysfunction in RIMS Biochemistry Department and since the present study was a hospital based study, it may not represent the whole population. But the study has identified the burden of thyroid dysfunction in Manipur and can be used as baseline data for future studies. The study demonstrates that the abnormal thyroid function is most commonly seen above 40 yrs of age. Hypothyroidism is the most common thyroid dysfunction in the population of Manipur.The present study also shows that hilly areas of Manipur has higher prevalence for thyroid dysfunction. So screening is needed for women above 40 yrs of age and also for people of hilly areas of Manipur.

\section{Acknowledgments}

I am very much grateful and highly obliged to my guide and my department for supporting me to do the study and also my statistician who helped me a lot for all the calculation and my colleague who always encouraged me to complete my study.

\section{References:}

[1]. N. Kochupillai, "Clinical endocrinology in India" in Current Science. Vol 79, P. Balram, Ed. India: Current science Association, 2000, p. 1061-7.

[2]. Baral N, Lamsal M, Koner BC, Koirala S. Thyroid dysfunction in eastern Nepal. Southeast Asian J Trop Med Public Health. 2002; 33:638-41.

[3]. Aminorroaya A, Janghorbani M, Amini A et al. the prevalence of thyroid dysfunction in an iodine sufficient area in Iran. Arch Iranian Med 2009; 12: 262-270.

[4]. [Last accessed on 2011 April 2]. Available from:http://www.ias.ac.in/currsci/oct252000/n\%20kochupillai.PDF.

[5]. Niafar M, Aliasgharzadeh A, Bahrami A. Prevalence of thyroid dysfunction in the elderly women of Iron. Endocrine Abstracts. 2009; 20:137.

[6]. P. Laurberg, K. M. Pedersen, A. Hreidarsson, N. Sigfusson, E. Iversen and P. R. Knudsen, "Iodine intake and the pattern of thyroid disorders: a comparative epidemiological study of thyroid abnormalities in the elderly in Iceland and in Jutland, Denmark" in The Journal of Clinical Endocrinology and Metabolism. Vol 83, 1998, pp. 765-9

[7]. Lamofon HA. Thyroid Disorders in Makkah, Saudi Arabia. Ozean J Appl Scien 2008; 1(1):55-8.

[8]. International Council for Control of Iodine Deficiency Disorders. UNICEF. World Health Organization. Assessment of iodine deficiency disorders and monitoring their elimination: a guide for programme managers. 2nd ed. Geneva: World Health Organization; 2001. 
[9]. Madhukar A, Prabin G, Nirakar R, Pratibha A, Dipendra RP. A Prevalence of thyroid dysfunction in Kathmandu University Hospital, Nepal. Biomedical Research 2010; 21 (4):411-15.

[10]. Seyed M, Asadollah H, Amir GK, Razieh SD, Atefe PA, Ali B. Alterations in TSH and Thyroid Hormone following mobile phone use. OMJ 2009; 24(4):274-78.

[11]. Vanderpump MP, Turnbridge WM. Epidemiology and prevention of clinical and subclinical hypothyroidism. Thyroid 2002; 12 (10):839-47.

[12]. Hueston WJ. Treatment of Hypothyroidism. Am Fam Physician 2001; 15; 64 (10): 1717-25.

[13]. Landenson PW, Singer PA, Ain KB. American thyroid association guide-lines for detection of thyroid dysfunction. Arch Intern Med 2000; 160: 1573-75.

[14]. Desai PM. Disorders of the Thyroid Gland in India. Indian J Pediatr. 1997; 64:11-20. [PubMed] 